\title{
Novel Use of Subcutaneous Octreotide via an Insulin Pump for Postural orthostatic Tachycardia Syndrome (POTS)
}

M Khan ${ }^{1}$, J Ouyang ${ }^{1}, K_{\text {Perkins }}^{1}$, F Joseph ${ }^{1}$

${ }^{1}$ Endocrinology \& Diabetes Department, Countess of Chester Hospital, Chester, UK

\section{Countess of Chester Hospital WHS}

NHS Foundation Trust

\section{Case History}

A 22 year old female presented in April 2002 with five episodic bouts of self-remitting palpitations, each lasting thirty seconds, over a period of four months.

Each episode was associated with chest discomfort, dyspnoea and dizziness.

Patient denied experiencing nausea, diaphoresis or syncope.

The patient had no significant medical or surgical history.

The patient was not taking any prescribed or over the counter medications.

Patient reported no history of such a presentation within the family and no significant family medical conditions.

\section{Clinical Course}

- Initial systemic examination revealed nothing of note par a regular resting heart rate of 99 beats per minute (bpm).

- Patient underwent a series of investigations which included full blood count, urea, electrolytes, thyroid function tests, 5 day Holter monitoring, chest X-ray, cardiomemo, electrophysiological studies and an echocardiogram.

- Despite such an exhaustive list of investigations, the only finding of note was sinus rhythm alternating with sinus tachycardia on Holter monitoring.

- Over a period of $\mathbf{3}$ years since initial presentation, her symptoms had escalated to the point where :

- She was forced to become wheelchair bound due to the severity of her orthostatic symptoms

- She was now experiencing multiple syncopal episodes resulting in long bone fractures - She was forced to withdraw from her medical training

- Her declining quality of life left her clinically depressed

In 2005, after 3 years of inconclusive studies, the patient underwent Tilt Table Testing (TTT).

- TTT revealed four pre-syncopal episodes associated with a sinus tachycardia and decrease in BP; maximum rise in heart rate of $42 \mathrm{bpm}$ and minimum BP recorded being $103 / 92 \mathrm{mmHg}$.

- TTT confirmed a diagnosis of PoTS which was later confirmed using autonomic testing (Table 1).

\begin{tabular}{|c|c|c|c|}
\hline \multicolumn{2}{|c|}{ Parameter } & \multirow{2}{*}{$\begin{array}{c}\begin{array}{c}\text { Blood Pressure } \\
\text { (mmHg) }\end{array} \\
135 / 90-145 / 91 \\
\end{array}$} & \multirow{2}{*}{$\begin{array}{c}\begin{array}{c}\text { Heart Rate } \\
\text { (beats per minute) }\end{array} \\
83-90\end{array}$} \\
\hline Head Position & Supine & & \\
\hline & $60^{\circ}$ head rise & $148 / 103-149 / 110$ & $108-109$ \\
\hline \multirow[t]{2}{*}{ Isometric Exercise } & Before & $135 / 90$ & 85 \\
\hline & During & $155 / 102$ & 95 \\
\hline \multirow[t]{2}{*}{ Mental Arithmetic } & Before & $132 / 99$ & 88 \\
\hline & During & $138 / 93$ & 87 \\
\hline \multirow[t]{2}{*}{ Cutaneous Cold } & Before & $138 / 90$ & 85 \\
\hline & During & $141 / 91$ & 85 \\
\hline \multicolumn{2}{|c|}{ Hyperventilation } & - & Marked Rise \\
\hline \multicolumn{2}{|c|}{ Deep Breathing } & - & $84-99$ \\
\hline \multirow{3}{*}{$\begin{array}{l}\text { Valsalva } \\
\text { manoeuvre }\end{array}$} & Resting & - & 78 \\
\hline & Phase II & - & 128 \\
\hline & Phase IV & - & 56 \\
\hline \multirow{3}{*}{ Bodily Position } & Supine & $135 / 90-145 / 91$ & $83-90$ \\
\hline & $\begin{array}{l}\text { After } 3 \text { minutes } \\
\text { of standing }\end{array}$ & $134 / 102$ & 111 \\
\hline & $\begin{array}{l}\text { After } 5 \text { minutes } \\
\text { of standing }\end{array}$ & $137 / 99$ & 115 \\
\hline \multicolumn{2}{|c|}{ Venepuncture } & \multicolumn{2}{|c|}{ Did not provoke symptoms/syncope } \\
\hline
\end{tabular}

Table 1: Results from autonomic testing. Presence of a high supine resting heart rate which excessively rose on postural challenge satisfied the criteria required for a diagnosis of PoTS'2.
Pof

\section{Treatment}

- Initial therapies involved trials of:

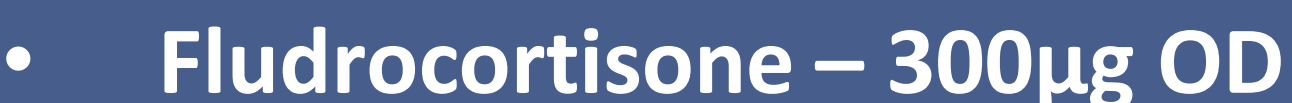

- Slow Sodium MR - 600mg up to 10 times a day

- Midodrine $-5 \mathrm{mg}$ TDS

Ivabradine - 7.5mg BD

- All therapies mentioned above proved either ineffective or caused intolerable side effects.

- She was later started on a trial of SC octreotide using gradual titration until she reached $300 \mu \mathrm{g} / 24 \mathrm{~h}-50 \mu \mathrm{g}$ every 90 minutes, six times a day

- Despite symptomatic relief from her PoTS, the patient reported unbearable abdominal cramps and diarrhoea following each injection of octreotide.

- In October 2011 she was seen by the endocrine team to consider the possibility of octreotide LAR but the concept of delivering SC octreotide via an Animas insulin pump (Figure 1) was discussed.

Patient wore the device for 7-12 hours during waking hours over which she received approximately $100 \mu \mathrm{g}$ per day at an infusion rate of $10 \mu \mathrm{g} /$ hour.

At two week follow up, patient reported being asymptomatic and not experiencing any side effects associated with the medication.

Since then, the patient has been able to walk independently and has been able to return to her medical training.

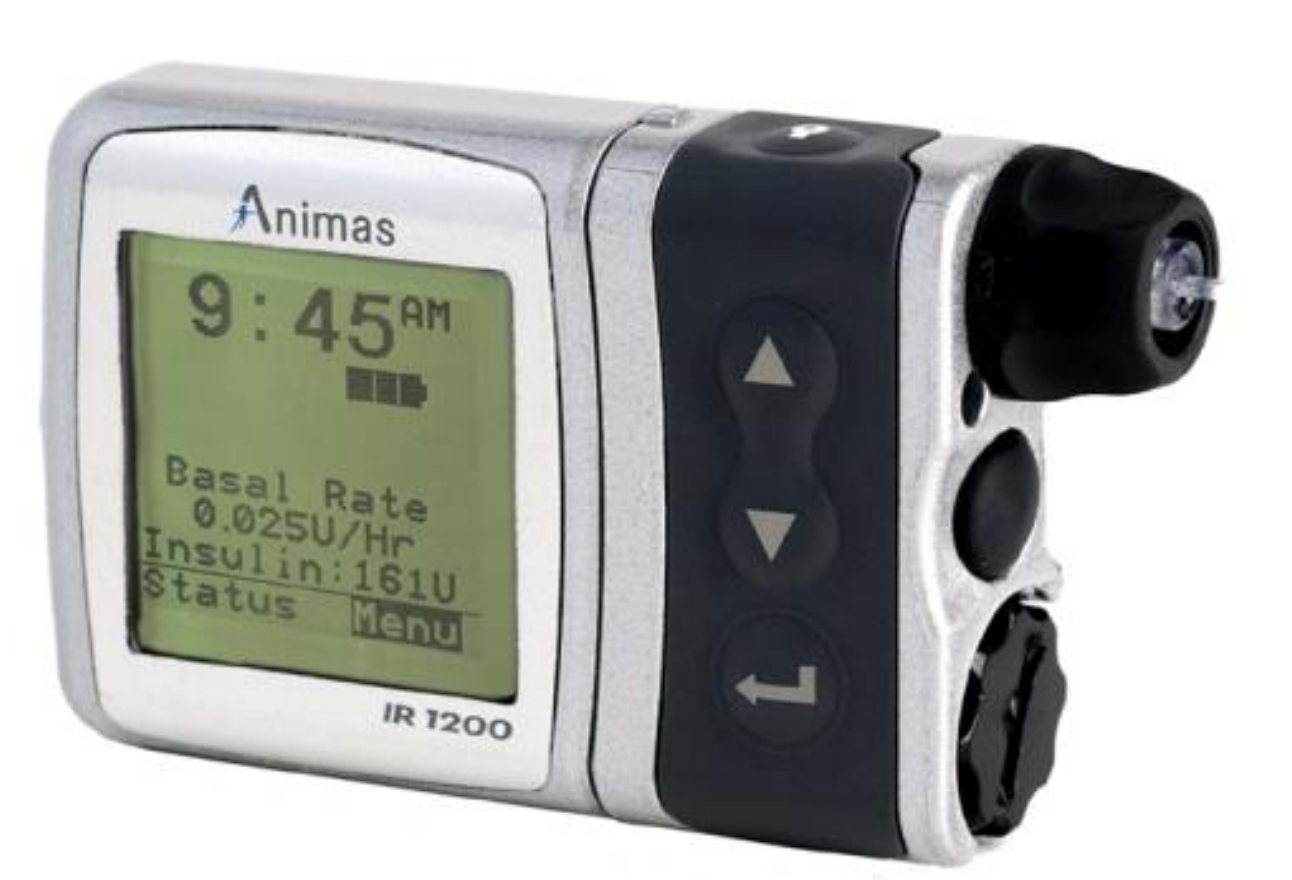

Figure 1: Animas Insulin Pump ${ }^{1}$

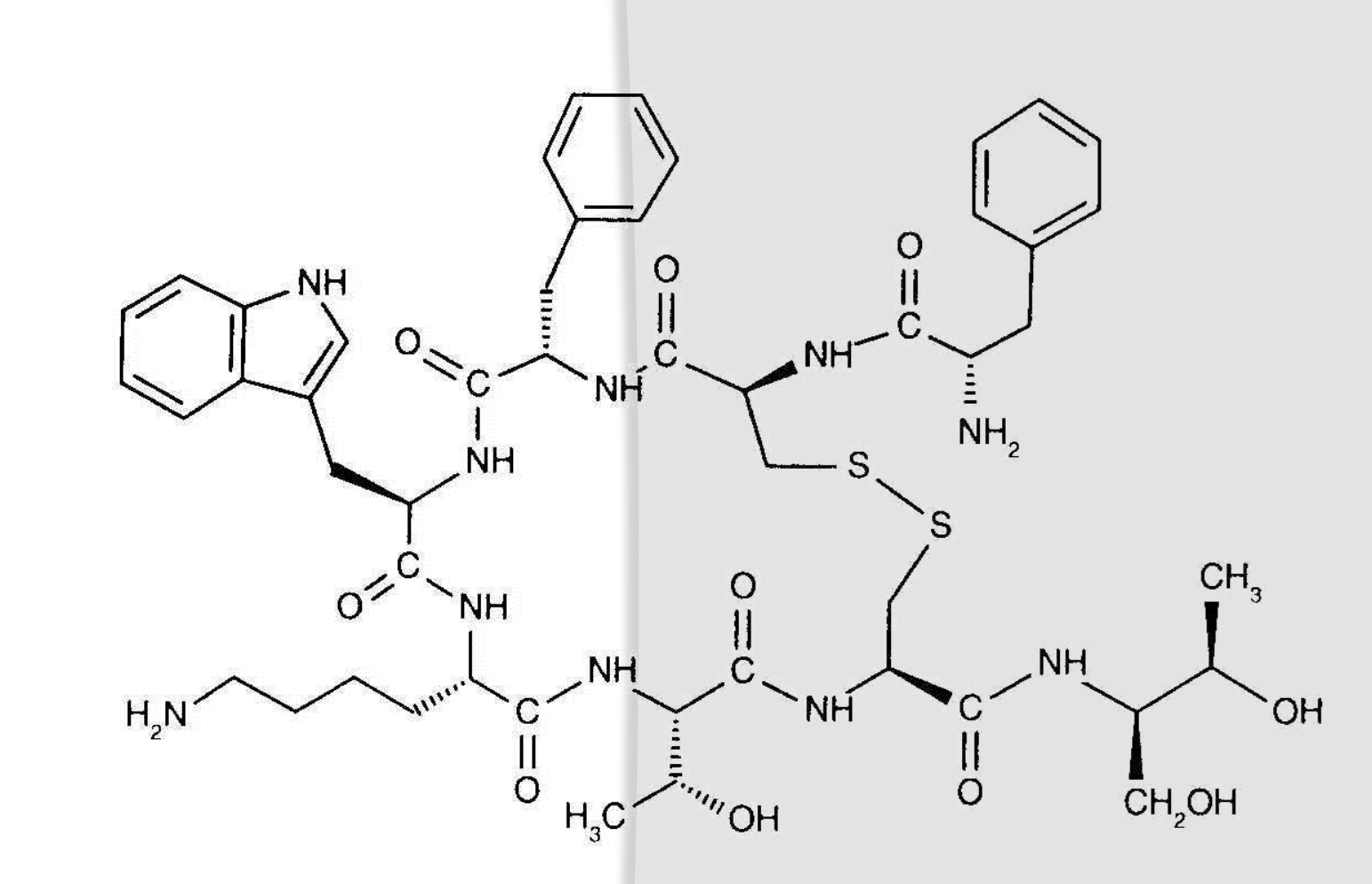

Figure 2: Molecular structure of Octreotide Acetate ${ }^{6}$

\section{Discussion}

PoTS reflects a dysfunction of the autonomic nervous system leading to several debilitating features.

Clinically, PoTS is defined by a sustained rise in heart rate of $\geq 30 \mathrm{bpm}$ or an increase in heart rate to $\geq 120 \mathrm{bpm}$ within 10 minutes on movement from supine to an upright position ${ }^{2}$.

Although several pharmaceutical options exist, one therapy includes the use of the somatostatin analogue octreotide ${ }^{3}$ (Figure 2).

- Octreotide acts as a somatostatin analogue, binding with high affinity to the somatostatin receptor subtypes 2 and $5^{4}$.

- Its proposed efficacy in PoTS centres on its ability to stimulate vasoconstriction in the systemic and splanchnic vasculature, thereby increasing venous return

- Despite SC and intramuscular long acting release (LAR) preparations being efficacious, the side effects, cost and inconvenience of frequent injections makes them far from ideal ${ }^{5}$.

Our case highlights how delivery of SC octreotide via an Animas insulin pump provides a novel mode of delivery of therapy for PoTS, whereby a lower dose can be given with fewer undesired effects. 